\title{
Supporting and Prohibiting Factors in Reflective Case Discussion (RCD)
}

\author{
Haeril Amir ${ }^{1, *}$, Andi Masyitha Irwan ${ }^{2}$, Ariyanti Saleh ${ }^{2}$ \\ ${ }^{\mathbf{1}}$ Faculty of Public Health, Universitas Muslim Indonesia, 90231, Makassar, Indonesia \\ ${ }^{2}$ Faculty of Nursing, Universitas Hasanuddin, 90231, Makassar, Indonesia
}

Received November 2, 2021; Revised December 16, 2021; Accepted January 16, 2022

\section{Cite This Paper in the following Citation Styles}

(a): [1] Haeril Amir, Andi Masyitha Irwan, Ariyanti Saleh, "Supporting and Prohibiting Factors in Reflective Case Discussion (RCD)," Nursing and Health, Vol. 7, No. 1, pp. 1 - 5, 2022. DOI: 10.13189/nh.2022.070101.

(b): Haeril Amir, Andi Masyitha Irwan, Ariyanti Saleh (2022). Supporting and Prohibiting Factors in Reflective Case Discussion (RCD). Nursing and Health, 7(1), 1 - 5. DOI: 10.13189/nh.2022.070101.

Copyright $\odot 2022$ by authors, all rights reserved. Authors agree that this article remains permanently open access under the terms of the Creative Commons Attribution License 4.0 International License

\begin{abstract}
Background: Reflective case discussion (RCD) is part of performance management development (PMD). RCD can be done in Hospital and Public Health Center. Nurses carried out RCD to discuss the Nursing issues and create a new Standard Operating Procedure (SOP) through reflective method. Objective: increase nurse professionalism and knowledge by holding discussions, sharing experiences so that mistakes in doing actions that have occurred do not happen again. All nurses must participate in RCD at least once a week. This activity was performed between half an hour and an hour. Method: Qualitative method with action research approach, involving 8 participants until the end in the operating room with three stages namely assessment, implementation and evaluation. Each stage is a reflective process, namely Plan, Action, Observe and Reflect stages. Results: This study found several themes regarding supporting factors, namely stakeholder support, and Nurse motivation, while inhibiting factors were lack of socialization and time and lack of evaluation and supervision. Conclusion: RCD did occur at Ibnu Sina Hospital because of lack of knowledge and socialization. Besides that, supervision and evaluation also did not work. The Head Nurse and Hospital management department must ensure that RCD activities are running and scheduled, because this activity is very important to improve the professionalism of nurses in their work as well as efforts to encourage the development of performance management.
\end{abstract}

Keywords Reflective Case Discussion (RCD), Nursing, Hospital

\section{Introduction}

The majority of Indonesia health workers are nurses. Based on data from the Indonesian Ministry of Health in 2017, from 601,228 health workers, nurses were 296,876 people or $49 \%$ of total health workers. In this case, the degree of expertise and professionalism of Nurse must be equal to its high number, particularly in carrying out their job. Nurse professionalism is described as a code of honor, integrity, and fairness, which is the system within the nursing norms and practice [1]. Nurse professionalism can be improved through the practice of reflection, according to research [2]. RCD on nurses increases the professionalism of the work and cooperation among colleagues. Implementation of the RCD environment of very clinical benefits [3].

Through the implementation of RCD, professionalism can be realized. Reflection is a process that connects experience and thought. It is helpful in the emergence of new knowledge and impacts the development of information on Nurse practices [4].

The reflection that was taken also connects the gap between theory and practice; other than that the reflection was allegedly helping Nurses achieve their professional competence [5].

Through practice, reflection can also be learned [6]. In addition to the high number of benefits of RCD, the issuance of Regulation of the Minister of Health of the Republic of Indonesia number 836/MENKES/SK/VI/2005 also become the reasons why this activity needs to be conducted regularly by the nurses. RCD is an "in- service training" which consists of several principles, commitment as a responsibility to guarantee the running of activities, improve 
the quality of human resources, and the team to encourage collaboration and increase knowledge [7].

Public health center and hospitals serve as a place to conduct RCD. Nurse's many obstacles in the work environment is why this activity is often ignored even not carried out.

This study discusses the factors supporting and inhibiting specific RCD at the Ibnu Sina Hospital YW-UMI Makassar. This hospital was chosen as the research site since its RCD is not implemented well. This particularly occurs in the operating room which is hectic. Therefore, in order to reduce stress within the room, a 30 minute reflection practice and experience discussion needs to be performed once a week. In addition, nurses in the operating room must have a lot of work experience so that reflection discussions are needed to exchange experiences with colleagues.

\section{Aim}

This study aims to identify the supporting and inhibiting factors of RCD in Ibnu Sina YW-UMI Hospital. Nursing Managers or hospital management can plan appropriate strategies to implement reflection discussions.

\section{Material \& Method}

This study uses a qualitative method with an action research approach. That action research's strength lies in its focus on generating solutions to practical problems and its ability to empower practitioners [8]. This research follows the action research theory of O'Leary's cycles of research.

This study involved 14 participants, but only 8 participants were involved up to the evaluation stage. Researchers took data using interview and direct observation techniques. Interviews were conducted with an in-depth interview technique. Based on interview guidelines, the action research method is carried out with several cycles, assessment, implementation, and evaluation. All cycles start from the Plan, Action, Observe and Reflect stages.

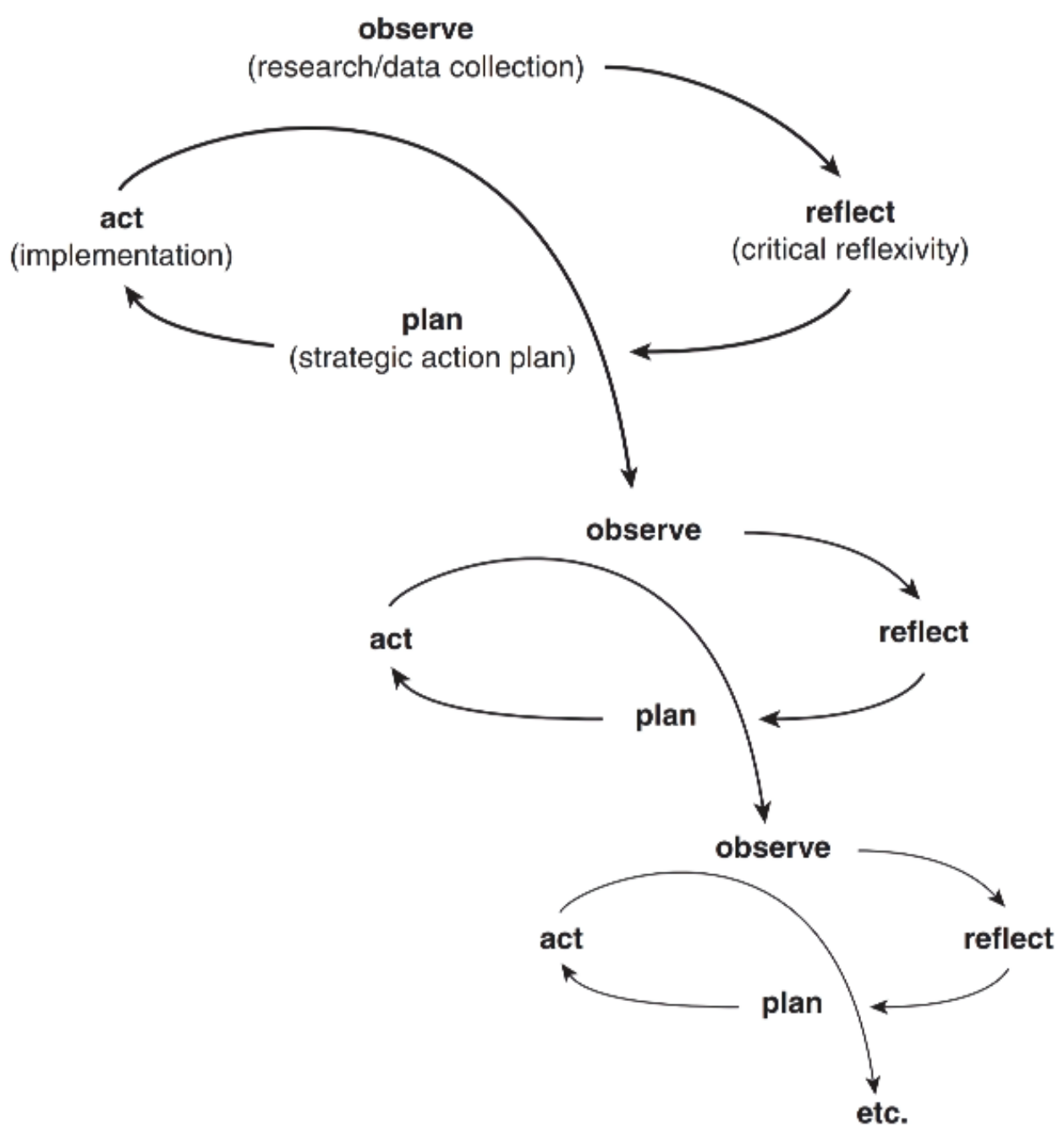

Figure 1. Theory of O'Learly Cycle 


\section{Action Research and Result}

I conducted this research from 10 September 2018 to 19 October 2018. The study was conducted in the operating room of the Ibnu Sina Hospital YW-UMI Makassar.

The research results are divided into several stages, namely, assessment, implementation, and evaluation stages.

\section{Assessment (September 10-24, 2018)}

Assessment is the initial cycle to determine the implementation of RCD in the operating room. The stage plan starts by planning a meeting with the participants. Interviews were conducted to the Head of the room and the Nurse so that the results of the interview gave rise to several themes namely

"Nurse's understanding of RCD, stakeholder support, lack of socialization and time, implementation of $R C D$, lack of evaluation and supervision and Nurse's self-motivation".

The implementation of RCD at the Ibnu Sina YW-UMI Makassar Hospital was based on interviews with participants, found several factors supporting RCD, namely the support of Stakeholders and Nurses' self-motivation. The following are excerpts of interviews with participants.

"In my opinion, personally, if possible, our head of nursing who is here is beneficial, this is most likely to happen, but maybe the nursing side is busy with itself until this activity does not occur".

The interview excerpt justifies stakeholder support to support the implementation of RCD activities. In this case the stakeholders referred to are the Hospital Director, the Head of Nursing and the Head of the Room.

The second supporting factor is nurses' self-motivation, following excerpts from interviews from participants:

"Essentially, there is a curiosity to desire, but the nursing section below does not support".

\section{Implementation (October 5-12, 2018)}

The second stage is implementation, actions taken in the form of explanations regarding RCD and role play implementation of RCD by raising cases that often occur in Operating rooms. This implementation is based on an agreement with the operating room nurse. This stage was done initially by explaining the RCD by Assafi's nurses during the meeting.

In the results of the second cycle, the researchers agreed on two actions in the form of an explanation of RCD and the implementation of RCD directly in the room. Based on the results of researchers' observations, there are still some things that are not done, for example, the presenter does not convey the rules of discussion and the conclusions of the discussion.
At this stage, nurses directly role-play about RCD. Some act as moderators, presenters, and participants.

\section{Evaluation (October 15-19, 2018)}

This stage is the final result of this research process. Researchers conducted in-depth interviews with all participants and directly observed at Ibnu Sina Hospital YW-UMI Makassar to ensure the implementation of RCD. The plan is carried out by evaluating the implementation of RCD. In this stage, all executing nurses were evaluated based on the interview guide prepared. At the observation stage, the researcher observed the implementation of RCD specifically in the operating room directly so that reflecting in this cycle directly made nurses aware of the importance of RCD in every room.

The results of the third cycle, namely, nurses can do RCD by the standard although it still needs to be improved continuously. This evaluation cycle directly accustoms the implementing nurse to the RCD.

"RCD is very good actually, and it can increase knowledge from discussions, share experiences too."

The interviews with these participants explain the importance of RCD activities carried out. Stakeholder support and nurses' self-motivation support the implementation of RCD in the Ibnu Sina Hospital YW-UMI Makassar.

\section{Discussion}

\section{Supporting factors}

Stakeholder support has a vital role in developing all staff and employees. The results of this study describe all stakeholders, the room head and the Head of nursing are very helpful in implementing nurses in making the changes themselves.

Malderen's [9] research illustrates the positive impulses on the private groups involved in RCD.

Oruke's [10] research is the role of stakeholders as a motivator for individual and group change also justifies the positive contribution of all parties to all forms of leadership activities. Stakeholder support can occur if the communication established between the executive nurse and the leader is effective; research Cummings [11] found that effective communication also helps establish interpersonal relationships.

Stakeholders contribute significantly to the development of nurses. Stakeholders must work together to realize the goals of the organization. In the future, stakeholder support for the implementation of RCD is a solution and a driving force for RCD to be carried out in every room on a regular and scheduled basis. Another supporting factor is nurses' self-motivation. Based on research results and operating room nurses, RCD is beneficial for sharing experiences. 
This being the basis of motivation in individuals is very important. Kinsella [12] provides an essential picture of the role of self-motivation that can be beneficial for improving the quality of practice in patients.

Kocman [13] classifying types of intrinsic motivation is also needed in competitive work. The operating nurse's intrinsic motivation can help them work more optimally.

Lambrou [14] identify the spirit of professionalism of nurses in work is primarily influenced by intrinsic motivation in him.

Nurses' motivation to do RCD influences their desire to find out further RCD. If the Nurse is motivated, satisfaction is also felt by the patient.

Nurses' professionalism improves through RCD. Therefore, this activity needs to be done constantly so that nurses can exchange their experiences during the reflective discussion and preventive efforts can be done on patient care mistakes.

\section{Prohibiting Factors}

Based on the results of research conducted, Nurses' understanding of RCD is very lacking. Barriers to nurses not to do RCD include lack of socialization and time.

Socialization of the RCD is essential and is the duty of the nursing department. The role of headroom and Head of nursing must be maximized in implementing the RCD. Dinmohammadi [15] describes socialization's purpose to recognize the roles, status and values needed in determining self-concept. Headroom and Head of nursing should continue to disseminate information on RCD activities. With socialization, it is believed that nurses in every room can understand and conduct RCD according to the rules and standards. Another finding from this study is the lack of nurse time in the operating room. Nurses in this room feel very busy because of a lack of energy. As a result, their time is taken up, and the workload increases. The workload is strongly influenced by satisfaction, stress, and productivity [16].

The hospital leadership and the nursing department should not allow this incident to continue. The leadership must draw up a strategic plan to overcome this so that future RCD becomes a priority and is planned possible, including the activity implementation time. Socialization and time play essential roles in the implementation of RCD The Headroom and the Head of Nursing need to make a particular schedule to monitor the implementation of RCD so that this activity is not ignored.

This study also found a lack of supervision and evaluation carried out by the nursing department on the implementation of RCD.

Nurse routines including RCD activities require supervision from superiors but due to work pressure and lack of knowledge. Supervision is the duty of Headroom and Head of nursing. Supervision can be done in the form of nursing supervision.

Banks [17] find research facts supervision as a guide, correcting errors and modifying techniques or the right way so that Karu and the Head of Nursing are also emphasized to know the procedures for implementing RCD. This study also found a lack of evaluation regarding the implementation of DRK, especially in the operating room. Evaluation is helpful promoting knowledge objectivity [18].

Supervision of the RCD implementation by the Nursing manager or the authorized party has never been carried out so that the RCD implementation is also irregular and tends to be ignored.

Supervision and evaluation are inseparable matters and are the responsibility of the leadership in each service. RCD must continue to be evaluated as learning material and improvement so that it will be much better.

Communication culture, error culture and fear of admitting mistakes can be avoided with the RCD approach because fellow nurses feel they need each other and are emphasized not to carry out a culture of blaming each other

\section{Effects of Implementing RCD}

Implementing of RCD at the implementation stage has a positive effect on increasing nurses' understanding of conducting RCD. Nurses involved in RCD can collaborate to provide professional action to patients.

Emich [19] explain the importance of collaboration and discussion with colleagues before giving action to patients.

Especially the RCD in the operating room of the Ibnu Sina Hospital YW-UMI that is necessary to raise cases that often occur, accustoming nurses to share experiences and exchange ideas. The RCD directly realizes to the operating theater nurse that all kinds of things need to be discussed to positively affect the patient.

\section{Implications for Nursing Development}

RCD is a discussion method for nurses. RCD was developed to exchange, experiences, and knowledge. The implications of RCD for nursing development, namely: Methods of solving nursing with discussion. Staff development by continuing to conduct RCD. Methods of sharing experiences with RCD.

\section{Research Limitation}

This study has limitations when conducting observations, and researchers only once ascertained the RCD running process after the study. In addition, not all participants were involved from the beginning of the assessment to the evaluation.

All respondents should consistently follow the research from beginning to end so that gaps in understanding about RCD do not occur. 
Future research is expected to involve more respondents besides that it needs to be done in another room besides the operating room

\section{Conclusion and Suggestion}

\section{Conclusion}

The supporting factors of RCD are stakeholder support and Nurses' self- motivation. RCD inhibiting factors include lack of socialization and monitoring and evaluation.

\section{Suggestion}

Form a team that works specifically to oversee the implementation of RCD, Hospital management must develop staff through ongoing forms of RCD training. Implementation of RCD must be carried out at least once a month and supervised by a team that has been formed.

\section{Acknowledgements}

The researcher thanks all those who contributed to this research.

\section{REFERENCES}

[1] Schmidt BJ, McArthur E. Professional nursing values: A concept analysis. Nurs Forum [Internet]. 2018;53(1):69-73. Available from: doi: 10.1111/nuf.12211

[2] Amir H, Irwan, Andi M, Saleh A. Gambaran Pelaksanaan Diskusi Refleksi Kasus (DRK) Dalam Mendukung Peingkatan Pengetahuan Dan Profesionalisme Perawat. J Keperawatan Muhammadiyah. 2019;4(1):74-80.

[3] Amir H, Sudarman S. Reflective Case Discussion (RCD) for Nurses: A Systematic Review. Str J Ilm Kesehat. 2020;9(2):332-7.

[4] Asselin M, Fain J. Effect of reflective practice education on self-reflection, insight, and reflective thinking among experienced nurses: a pilot study. J Nurses Prof Dev [Internet]. 2013;29(3):111-9. Available from: doi: 10.1097/NND.0b013e318291c0cc

[5] Brubakken K, Grant S, Johnson M, Kollauf C. Reflective practice: a framework for case manager development. Prof Case Manag [Internet]. 2011;16(4):170-9. Available from: doi: 10.1097/NCM.0b013e318216af96

[6] Choperena A, Oroviogoicoechea C, Salcedo A, Moreno I,
Jones D. Nursing narratives and reflective practice: A theoretical review. J Adv Nurs [Internet]. 2019;75(8):163747. Available from: doi: $10.1111 /$ jan. 13955

[7] Kemenkes RI. Keputusan Menteri Kesehatan Republik Indonesia Nomor 836/MENKES/SK/VI/2005 Tentang Pedoman Pengembangan Manajemen Kinerja Perawat dan Bidan [Internet]. Kementerian Kesehatan Republik Indonesia. 2005. Available from: https://peraturan.bkpm.g o.id/jdih/userfiles/batang/KEPMENKES_836_2005.pdf

[8] Meyer. Using qualitative methods in health related action research. Br Med J. 2000;320:178-181.

[9] Malderen L, Vriendt P, Mets T, Verte D, Gorus E. Experiences and Effects of Structurally Involving Residents in the Nursing Home by Means of Participatory Action Research: A Mixed Method Study. J Am Med Dir Assoc [Internet]. 2017;18(6):495-502. Available from: doi: 10.1016/j.jamda.2016.12.072

[10] O’Rourke T, Higuchy K, Hogg W. Stakeholder Participation in System Change: A New Conceptual Model. Wordview Evid Based Nurs [Internet]. 2016;13(4):261-9. Available from: doi: 10.1111/wvn.12165.

[11] Cummings GG, MacGregor T, Davey M, Lee H, Wong CA, Lo E, et al. Leadership styles and outcome patterns for the nursing workforce and work environment: A systematic review. Int J Nurs Stud [Internet]. 2010;47(3):363-85. Available from: http://dx.doi.org/10.1016/j.ijnurstu.2009.0 8.006

[12] Kinsella D, Fry M, Zecchin A. Motivational factors influencing nurses to undertake postgraduate hospital-based education. Nurse Educ Pract [Internet]. 2018;31:54-60. Available from: https://doi.org/10.1016/j.nepr.2018.04.011

[13] Kocman A, Weber G. Job Satisfaction, Quality of Work Life and Work Motivation in Employees with Intellectual Disability: A Systematic Review. J Appl Res Intellect Disabil. 2018;31(1):1-22.

[14] Lambrou P, Kontodimopoulos N, Niakas D. Motivation and job satisfaction among medical and nursing staff in a Cyprus public general hospital. Hum Resour Health [Internet]. 2010; 8(1):26. Available from: http://www.hum an-resources-health.com/content/8/1/26

[15] Dinmohammadi M, Peyrovi H, Mehrdad N. Concept Analysis of Professional Socialization in Nursing. Nurs Forum. 2013;48(1):26-34.

[16] Alghamdi MG. Nursing workload: A concept analysis. J Nurs Manag. 2016;24(4):449-57.

[17] Banks D, Clifton A V., Purdy MJ, Crawshaw P. Mental health nursing and the problematic of supervision as a confessional act. J Psychiatr Ment Health Nurs. 2013;20(7):595-600.

[18] Polit D, Beck C. Nursing research; Generating and Assesing Evidence for Nursing Practice. Philadelphia: Lippincot Williams \&Wilkins; 2012.

[19] Emich C. Conceptualizing collaboration in nursing. Nurs Forum. 2018;53(4):567-73. 